David Hirsch, ${ }^{1}$ Sam Motto, ${ }^{2}$ Gary Peyton, ${ }^{3}$ and Harold Beeson ${ }^{4}$

\title{
Proficiency Testing for Evaluating Aerospace Materials Test Anomalies
}

\begin{abstract}
REFERENCE: Hirsch, D., Motto, S., Peyton, G., and Beeson, H., "Proficiency Testing for Evaluating Aerospace Materials Test Anomalies,” Flammability and Sensitivity of Materials in Oxygen-Enriched Atmospheres: Eleventh Volume, ASTM STP 1479, D. B. Hirsch, R. Zawierucha, T. A. Steinberg, and H. Barthelemy, Eds., ASTM International, West Conshohocken, PA, 2006.
\end{abstract}

ABSTRACT: ASTM G 86 and ASTM G 74 are commonly used to evaluate materials susceptibility to ignition in liquid and gaseous oxygen systems. However, the methods have been known for their lack of repeatability. The inherent problems identified with the test logic would either not allow precise identification or the magnitude of problems related to running the tests, such as lack of consistency of systems performance, lack of adherence to procedures, etc. Excessive variability leads to increasing instances of accepting the null hypothesis erroneously, and so to the false logical deduction that problems are nonexistent when they really do exist. This paper attempts to develop and recommend an approach that could lead to increased accuracy in problem diagnostics by using the $50 \%$ reactivity point, which has been shown to be more repeatable. The initial tests conducted indicate that PTFE and Viton ${ }^{\circledR} \mathrm{A}$ (for pneumatic impact) and Buna S (for mechanical impact) would be good choices for additional testing and consideration for inter-laboratory evaluations. The approach presented could also be used to evaluate variable effects with increased confidence and tolerance optimization.

KEYWORDS: test methods, proficiency testing, precision, ignition, pneumatic impact, mechanical impact, oxygen compatibility, polymers

\section{Introduction}

Proficiency testing is commonly defined as a means of checking laboratory testing performance through periodic inter-laboratory tests. For many test methods, results from proficiency testing are good indicators of a laboratory's testing capability. Information obtained from proficiency testing helps to identify problems in a laboratory and lead to solutions. In addition to assisting laboratories in making improvements when necessary, results from proficiency testing can be used to improve test methods and contribute to the development of precision and accuracy statements $[1,2]$.

${ }^{1}$ Aerospace Engineering Manager, Honeywell Technology Solutions Inc., NASA Johnson Space Center White Sands Test Facility, P.O. Box 20, Las Cruces, NM 88004.

2 Test Engineer, Honeywell Technology Solutions Inc., NASA Johnson Space Center White Sands Test Facility, P.O. Box 20, Las Cruces, NM 88004.

3 Materials and Test Coordinator, Honeywell Technology Solutions Inc., NASA Johnson Space Center White Sands Test Facility, P.O. Box 20, Las Cruces, NM 88004.

${ }^{4}$ NASA Laboratories Office Deputy Chief, NASA Johnson Space Center White Sands Test Facility, P.O. Box 20, Las Cruces, NM 88004. 
ASTM Standard Test Method for Determining Ignition Sensitivity of Materials to Mechanical Impact in Ambient Pressure Liquid Oxygen and Pressurized Liquid and Gaseous Oxygen (G 86) and ASTM Standard Test Method for Ignition Sensitivity of Materials to Gaseous Fluid Impact (G 740) are commonly used to evaluate susceptibility to ignition in liquid and gaseous oxygen systems [3-7]. However, the methods have been known for their lack of repeatability [8-12]. The inherent problems identified with the test logic would either not allow precise identification or the magnitude of problems related to running the tests, such as lack of consistency of systems performance, lack of adherence to procedures, etc. Excessive variability leads to increasing instances of accepting the null hypothesis erroneously, and so to the false logical deduction that problems are nonexistent when they really do exist [13].

A previous study [14] identified the importance of properly selecting test conditions for evaluating repeatability of aerospace materials flammability testing and provided an approach that would increase the diagnostics capability of inter-laboratory flammability testing. This paper attempts to develop and recommend an approach that could lead to increased accuracy in problem diagnostics related to some test methods used to evaluate materials oxygen compatibility.

\section{Experimental}

\section{Materials}

The materials evaluated are described in Table 1. The mechanical impact samples were 17-mm diameter discs, while the pneumatic impact samples were 4.8-mm diameter discs. The sample thickness was approximately $1.5 \mathrm{~mm}$.

TABLE 1 -Materials tested.

Generic or Trade Name Chemical Name or Composition

\begin{tabular}{ll}
\hline Plastics & \\
\hline Zytel $42^{\circledR \text { a }}$ & polyamide 6,6 (Nylon 6,6) \\
PTFE & polytetrafluoroethylene \\
Kel-F $81^{\circledR}$ b & polychlorotrifluoroethylene \\
Neoflon M400H ${ }^{\circledR \text { c }}$ & polychlorotrifluoroethylene \\
\hline Elastomers & \\
\hline Silicone rubber & polysiloxane \\
Viton ${ }^{\circledR}$ d A & copolymer of vinylidene fluoride and hexafluoropropylene \\
Buna S & polystyrene/butadiene \\
Neoprene & polychloroprene \\
EPDM & polyethylene/propylene diene \\
Nitrile rubber & polyacrylonitrile/butadiene \\
\hline${ }^{\mathrm{a}}$ Zytel ${ }^{\circledR}$ is a registered trademark of E. I. DuPont de Nemours \& Co., Wilmington, DE. \\
${ }^{\mathrm{b}}$ Kel- $\mathrm{F}^{\circledR}$ is a registered trademark of M. W. Kellogg Co., Jersey City, NJ. \\
${ }^{\mathrm{c} N e o f l o n}{ }^{\circledR}$ is a registered trademark of Daikin America Inc., Orangeburg, NY. \\
${ }^{\mathrm{d}}$ Viton ${ }^{\circledR}$ is a registered trademark of DuPont Dow Elastomers, Wilmington, DE.
\end{tabular}




\section{Test Conditions and Methods}

Pneumatic impact testing was conducted following ASTM G 74, which evaluates the relative sensitivity of materials to dynamic pressure impacts. First, a sample was placed in the specimen area of the test chamber subassembly, and then an upstream accumulator was pressurized with gaseous oxygen (GOX). Next, the chamber was purged with GOX, and the sample was exposed to a sequence of five impacts by opening a high-speed valve between the accumulator and the test chamber. The test chamber was pressurized from ambient pressure to $95 \%$ of test pressure in less than $50 \mathrm{~ms}$. A reaction was indicated by an abrupt increase in test specimen temperature or by an obvious change in material appearance, as observed during posttest examination.

The tests were conducted following the Bruceton method [15]. The first test was conducted at a pressure estimated to result in a $50 \%$ probability of reaction. For subsequent testing, if a reaction occurred, the next test was conducted at the next lower pressure level; if no reaction occurred, the next test was conducted at the next higher pressure. The test sequence was completed when 20 tests were performed, counting from the first test that produced a change in results. The 50\% reaction pressure level was determined from [15]:

where:

$$
\mathrm{p}_{50}=\mathrm{p}_{0}+\mathrm{d}[(\mathrm{A} / \mathrm{N}) \pm 0.5]
$$

$\mathrm{p}_{50}=50 \%$ reaction pressure

$\mathrm{p}_{0}=$ lowest pressure at which no reactions were observed

$\mathrm{d}=$ pressure increment, $1.7 \mathrm{MPa}$

$\mathrm{A}=$ sum of frequency of occurrence at each pressure increment times the number of increments above the p value for each observation in the $\mathrm{N}$ total

$\mathrm{N}=$ total number of less frequent events (reactions or no reactions) from the last 20 samples tested

Ambient-pressure mechanical impact testing in liquid oxygen (LOX) and mechanical impact tests in GOX at 20.6 MPa were conducted per ASTM G 86. For tests in ambient-pressure liquid oxygen, each sample was placed in an aluminum sample cup on top of a stainless steel disc and prechilled in LOX for at least $40 \mathrm{~min}$. A prechilled striker pin was then centered in the sample cup. The sample cup was placed in a sample holder that was cooled with liquid nitrogen. A 9.07-kg plummet was dropped from a preset height on the striker pin, which in turn impacted the sample. Visual flash, audible report, or charring of the sample was considered evidence of reactions.

For mechanical impact tests in pressurized GOX, each sample was placed in a sample cup with an Inconel 718 base, which was then mounted in a test chamber. The test chamber was purged with the test gas and then pressurized to 20.6 MPa with GOX. A 9.07-kg plummet was dropped from selected heights onto a counterloader pin, which transmitted the energy to the test sample by means of a striker pin. Abrupt increases of test chamber pressure or temperature, light emission, or material charring were considered evidence of reaction.

The mechanical impact test logic used was similar to the logic used for pneumatic impact. The first test was conducted at a plummet height estimated to produce $50 \%$ reactions. For subsequent testing, if a reaction occurred, the next test was conducted at the next lower height; if no reaction occurred, the next test was conducted at the next higher level. The test sequence was completed when 20 tests were performed, counting from the first test that produced a change in 
results in successive energy levels. Alternatively, additional tests were conducted on selected materials to determine if performing 30 tests instead of 20 would make a difference in the 50\% point determination. The 50\% impact height that resulted in 50\% reactions was determined with an equation similar to equation 1 . The $50 \%$ mechanical impact test methodology is described in detail elsewhere [16]. For all test methods used, the testing was repeated to obtain five replicates.

\section{Results and Discussion}

The pneumatic and mechanical 50\% reactivity levels are summarized in Tables 2 and 3.

TABLE 2-Pneumatic impact 50\% reaction levels.

\begin{tabular}{lccc}
\hline Material & $50 \%$ point, $^{\text {a }}$ MPa & $\begin{array}{c}\text { Standard } \\
\text { deviation, MPa }\end{array}$ & $\begin{array}{c}\text { Coefficient of } \\
\text { variation }\end{array}$ \\
\hline Silicone & 20.80 & 3.49 & 0.168 \\
PTFE & 21.91 & 1.02 & 0.047 \\
Viton A & 16.11 & 0.85 & 0.053 \\
Kel-F & 24.17 & 1.70 & 0.070 \\
Neoflon M400H & 24.46 & 2.68 & 0.110 \\
\hline
\end{tabular}

${ }^{\mathrm{a}}$ Average of five tests

Statistically there were no differences at the 95\% significance level between the average values obtained for the 50\% reactivity points for Kel-F 81 and Neoflon M400H. PTFE and Viton A resulted in the lowest coefficient of variation, and would be good choices for additional testing and consideration in inter-laboratory evaluations.

TABLE 3-Mechanical impact 50\% reaction levels.

\begin{tabular}{lccccccc}
\hline Material & $\begin{array}{c}\text { Test } \\
\text { Environment }\end{array}$ & \multicolumn{3}{c}{ 20 samples } & \multicolumn{3}{c}{30 samples } \\
\cline { 3 - 7 } & $\begin{array}{c}50 \% \\
\text { Point, } \\
\text { J }\end{array}$ & $\begin{array}{c}\text { Standard } \\
\text { Deviation, } \\
\mathrm{J}\end{array}$ & $\begin{array}{c}\text { Coefficient } \\
\text { of Variation }\end{array}$ & $\begin{array}{c}50 \% \\
\text { Point, } \\
{ }^{c}{ }^{c}\end{array}$ & $\begin{array}{c}\text { Standard } \\
\text { Deviation, } \\
\mathrm{J}\end{array}$ & $\begin{array}{c}\text { Coefficient } \\
\text { of Variation }\end{array}$ \\
\hline EPDM & LOX $^{\mathrm{a}}$ & 55.0 & 7.8 & 0.142 & 55.5 & 6.1 & 0.110 \\
Silicone & LOX $^{\mathrm{a}}$ & 25.3 & 5.6 & 0.221 & $\ldots$ & $\ldots$ & $\ldots$ \\
Nitrile & LOX $^{\mathrm{a}}$ & 44.1 & 7.3 & 0.166 & 44.8 & 5.3 & 0.118 \\
Neoprene & LOX $^{\mathrm{a}}$ & 54.5 & 5.9 & 0.108 & 51.5 & 5.8 & 0.113 \\
Buna S & LOX $^{\mathrm{a}}$ & 65.3 & 7.9 & 0.121 & 65.9 & 4.3 & 0.065 \\
Buna S & GOX $^{\mathrm{b}}$ & 50.6 & 5.7 & 0.113 & 50.7 & 5.3 & 0.105 \\
\hline
\end{tabular}

${ }^{\mathrm{a}}$ Tests conducted at White Sands Test Facility (WSTF) ambient pressure, $85 \mathrm{kPa}$

b Tests conducted at 20.6 MPa

${ }^{\mathrm{c}}$ Average of five tests

Because of system limitations, the mechanical impact 50\% point could not be obtained for materials with less reactivity. In ambient-pressure LOX, silicone had a much lower mechanical impact 50\% reactivity level than the other materials considered less oxygen compatible. Statistically there were no differences at the 95\% significance level between the average values obtained with 20 and 30 samples; however, testing 30 samples reduced the coefficient of variation significantly in most instances. Consequently, determining the $50 \%$ point with 30 
samples will reduce the instances of accepting the null hypothesis erroneously. Buna $S$ resulted in lowest variability in mechanical impact and is the material of choice for further intra- and inter-laboratory variability studies.

The pneumatic and mechanical impact results have shown to be affected by many variables $[10,12]$. The precision and accuracy of these tests could be affected by the high-speed valve performance (for pneumatic impact), consistency of impact energy imparted to the sample (for mechanical impact), precision and accuracy of pressure measurements, and consistency of sample preparation. The tolerances used for test monitoring and variable control could also affect the results. Tolerance optimization is desirable, since too large a tolerance leads to excessive data variability, while a smaller tolerance than needed results in unnecessary expenses. Evaluation of variable effects and tolerance optimization may be achieved with a higher confidence if a repeatable test logic such as the $50 \%$ reactivity is used in a multifactorial experimental design, such as the Plackett-Burman approach [17].

Reaction frequencies in mechanical impact tests are presented in Tables 4 and 5. Because of the test logic, data presented in Tables 4 and 5 concentrate around the $50 \%$ reactivity point.

TABLE 4-Mechanical impact reaction frequencies for materials at various impact energies.

Selected values for conditions at which at least 20 samples were tested.

Tests conducted in LOX at the WSTF facility pressure, $85 \mathrm{kPa}$.

\begin{tabular}{crrrrrr}
$\begin{array}{c}\text { Impact } \\
\text { energy, J }\end{array}$ & Zytel & EPDM & Nitrile & Neoprene & Viton A & Buna S \\
\hline 98 & 63.0 & $\ldots$ & $\ldots$ & $\ldots$ & 62.5 & $\ldots$ \\
86 & 61.1 & $\ldots$ & $\ldots$ & $\ldots$ & 55.9 & 64.0 \\
74 & 42.1 & $\ldots$ & $\ldots$ & $\ldots$ & 40.0 & 61.9 \\
65 & 42.4 & 60.0 & $\ldots$ & 69.2 & $\ldots$ & 38.5 \\
56 & 28.6 & 55.3 & 68.0 & 61.0 & $\ldots$ & 37.5 \\
49 & $\ldots$ & 46.3 & 62.2 & 42.5 & $\ldots$ & $\ldots$ \\
43 & $\ldots$ & 13.6 & 44.1 & 31.8 & $\ldots$ & $\ldots$ \\
37 & $\ldots$ & $\ldots$ & 44.0 & $\ldots$ & $\ldots$ & $\ldots$ \\
\hline
\end{tabular}

TABLE 5-Mechanical impact reaction frequencies for materials at various impact energies. Selected values for conditions at which at least 20 samples were tested.

Tests conducted in GOX at 20.6 MPa.

\begin{tabular}{lrrrrrr}
\hline $\begin{array}{c}\text { Impact } \\
\text { energy, J }\end{array}$ & EPDM & Silicone & Nitrile & Neoprene & Viton A & Buna S \\
\hline 98 & 73.1 & $43.1^{\text {a }}$ & 25.8 & 62.9 & $\ldots$ & $\ldots$ \\
86 & 58.3 & $43.2^{\text {a }}$ & 8.3 & $44.4^{\text {a }}$ & $45.8^{\text {a }}$ & $\ldots$ \\
74 & 41.2 & 31.8 & $\ldots$ & $57.1^{\text {a }}$ & $52.2^{\text {a }}$ & $\ldots$ \\
65 & 29.0 & $\ldots$ & $\ldots$ & 33.3 & 43.5 & 85.2 \\
56 & $\ldots$ & $\ldots$ & $\ldots$ & $\ldots$ & $\ldots$ & 54.5 \\
49 & $\ldots$ & $\ldots$ & $\ldots$ & $\ldots$ & $\ldots$ & 47.5 \\
43 & $\ldots$ & $\ldots$ & $\ldots$ & $\ldots$ & $\ldots$ & 29.2 \\
\hline
\end{tabular}

a As indicated, five 50\% reactivity point evaluations were conducted for each material. More extensive data are required to draw conclusions about the reactivity inversions noted. 
In mechanical impact tests in ambient-pressure LOX, materials considered more oxygencompatible (Viton A, Zytel) performed better than the others (EPDM, Nitrile, Neoprene). It is interesting to note that in this test the vast majority of reactions on Zytel were not obtained at the first impact.

In mechanical impact tests in pressurized GOX, some materials (Nitrile, EPDM to an extent) performed better than others traditionally considered suitable for oxygen service (such as Viton A). This confirms previous data that indicate Nitrile rubber was less reactive than Viton A and Silicone under conditions of higher impact energies [18].

\section{Conclusions and Recommendations}

ASTM G 86 and ASTM G 74 are commonly used to evaluate materials susceptibility to ignition in liquid and gaseous oxygen systems. The methods have been known for their lack of repeatability. The inherent problems identified with the test logic would either not allow precise identification or the magnitude of problems related to running the tests, such as lack of consistency of systems performance, lack of adherence to procedures, etc.

Excessive variability leads to increasing instances of accepting the null hypothesis erroneously, and so to the false logical deduction that problems are nonexistent when they really do exist. This paper attempts to develop and recommend an approach that could lead to increased accuracy in problem diagnostics by using the $50 \%$ reactivity point, which has been shown to be more repeatable. Although statistically for mechanical impact there were no differences at the $95 \%$ significance level between the 50\% reactivity average values obtained with 20 and 30 samples, testing 30 samples reduced the coefficient of variation significantly in most instances. Consequently, determining the 50\% point with 30 samples will reduce the instances of accepting the null hypothesis erroneously. The initial tests conducted indicate that PTFE and Viton A (for pneumatic impact) and Buna S (for mechanical impact) would be good choices for additional testing and consideration in inter-laboratory evaluations. The approach could also be used to evaluate variable effects with increased confidence and tolerance optimization.

\section{References}

[1] Kirckpatrick, D. and Horlick, J., "Proficiency Testing: An Essential Element of Laboratory Performance Evaluation and Accreditation,” Evaluation and Accreditation of Inspection and Test Activities, ASTM STP 814, H. Schock, Ed., American Society for Testing and Materials, Philadelphia, PA, 1983, pp. 128-140.

[2] Horlick, J., "Interlaboratory and Intralaboratory Proficiency Testing," Accreditation Practices for Inspections, Tests, and Laboratories, ASTM STP 1057, H. E. Schock, Jr., Ed., American Society for Testing and Materials, Philadelphia, PA, 1989, pp. 85-9.

[3] Bryan, C. J., "NASA Mechanical Impact Testing in High Pressure Oxygen,” Flammability and Sensitivity of Materials in Oxygen-Enriched Atmospheres, ASTM STP 812, B. L. Werley, Ed., American Society for Testing and Materials, Philadelphia, PA, 1983, pp. 9-42.

[4] Stradling, J. S., Pippen, D. L., and Frye, G. W., "Techniques Employed by the NASA White Sands Test Facility to Ensure Oxygen System Component Safety,” Flammability and Sensitivity of Materials in Oxygen-Enriched Atmospheres, ASTM STP 812,

B. L. Werley, Ed., American Society for Testing and Materials, Philadelphia, PA, 1983, pp. 97-107.

[5] Bryan, C. J. and Olsen, M. G. "Procedure for the Selection of Materials for Use in Oxygen Systems at the John F. Kennedy Space Center," Flammability and Sensitivity of Materials 
in Oxygen-Enriched Atmospheres, ASTM STP 986, D. W. Schroll, Ed., American Society for Testing and Materials, Philadelphia, PA, 1988, pp. 262-267.

[6] Stradling, J. S., and Pippen, D., Testing of Materials in Oxygen for Kennedy Space Center, Summary Report No. KSC-WSTF-24, Johnson Space Center White Sands Test Facility, Las Cruces, NM, August 1974.

[7] Pippen, D. L. and Stradling, J. S., "Techniques for Determination of Flash and Fire Points and Impact Sensitivity of Materials in a Gaseous Oxygen Environment,” Materials Research and Standards, June 1971, pp. 35-43, 53.

[8] Moffett, G. E., Schmidt, N. E., Pedley, M. D., and Linley, L. J., “An Evaluation of the Liquid Oxygen Mechanical Impact Test,” Flammability and Sensitivity of Materials in Oxygen-Enriched Atmospheres: Fourth Volume, ASTM STP 1040, J. M. Stoltzfus, F. J. Benz, and J. S. Stradling, Eds., American Society for Testing and Materials, Philadelphia, PA, 1989, pp. 11-22.

[9] Schmidt, N. E., Moffett, G. E., Pedley, M. D., and Linley, L. J., "Ignition of Nonmetallic Materials by Impact of High-Pressure Oxygen II: Evaluation of Repeatability of Pneumatic Impact Test," Flammability and Sensitivity of Materials in Oxygen-Enriched Atmospheres: Fourth Volume, ASTM STP 1040, J. M. Stoltzfus, F. J. Benz, and J. S. Stradling, Eds., American Society for Testing and Materials, Philadelphia, PA, 1989, pp. 23-37.

[10] Moffett, G. E., Pedley, M. D, Schmidt, N., Williams, R. E., Hirsch, D., and Benz, F. J., "Ignition of Nonmetallic Materials by Impact of High-Pressure Gaseous Oxygen," Flammability and Sensitivity of Materials in Oxygen-Enriched Atmospheres: Third Volume, ASTM STP 986, D. W. Schroll, Ed., American Society for Testing and Materials, Philadelphia, PA, 1988, pp. 218-232.

[11] Blackstone, W. R. and Ku, P. M., “An Assessment of Impact Test Techniques for Determining the Fire or Explosion Hazards of Materials Exposed to Liquid Oxygen," Materials Research and Standards, June 1971, pp. 30-35, 52.

[12] McColskey, J. D., Reed, J. D., Simon, N. J., and Bransford, J. W., "Recommended Changes in ASTM Test Methods D2512-82 and G86-84 for Oxygen Compatibility Mechanical Impact Tests on Metals," Flammability and Sensitivity of Materials in Oxygen-Enriched Atmospheres: Fifth Volume, ASTM STP 1111, J. M. Stoltzfus and K. McIlroy, Eds., American Society for Testing and Materials, Philadelphia, PA, 1991, pp. 126-153.

[13] Hirsch, D., “Test Methods: Phenomenology and Statistics,” Presented at the $14^{\text {th }}$ International Standardization Organization Plenary Meeting of the Technical Committee on Space Systems and Operations, Moscow, Russia, May 2004.

[14] Hirsch, D. and Beeson, H., "An Approach to Evaluate Precision and Inter-Laboratory Variability of Flammability Test Methods for Aerospace Materials,” $35^{\text {th }}$ International Conference on Environmental Systems and $8^{\text {th }}$ European Symposium on Space Environmental Control Systems, Rome, Italy, July 11-14, 2005.

[15] Dixon, W. J. and Massey, F. J., Introduction to Statistical Analysis, McGraw-Hill, New York, NY, 1969, pp. 377-394.

[16] Beeson, H. D., Hshieh, F., and Hirsch, D. B., "Ignitibility of Advanced Composites in Liquid and Gaseous Oxygen," Flammability and Sensitivity of Materials in OxygenEnriched Atmospheres: Eighth Volume, ASTM STP 1319, W. T. Royals, T. C. Chou, and T. A. Steinberg, Eds., American Society for Testing and Materials, Philadelphia, PA, 1997, pp. 421-431.

[17] Plackett, R. L. and Burman, J. P., “The Design of Optimum Multifactorial Experiments,” Biometrika, Vol. 33, 1946, pp. 305-325.

[18] Hirsch, D., Hshieh, F., Beeson, H., and Bryan, C. "Ignitibility in Air, Gaseous Oxygen and Oxygen-Enriched Environments of Polymers Used in Breathing-Air Devices,"

Flammability and Sensitivity of Materials in Oxygen-Enriched Atmospheres: Eighth Volume, ASTM STP 1319, W. T. Royals, T. C. Chou, and T. A. Steinberg, Eds., American Society for Testing and Materials, Philadelphia, PA, 1997, pp. 359-369. 